\title{
Development of an Automated Real-Time System for Soil Temperature and Moisture Measurement
}

\author{
Anibal Mantovani Diniz ${ }^{1}$, Márcio Antonio Vilas Boas ${ }^{1}$, Marcelo Bevilacqua Remor ${ }^{1}$, \\ Jair Antonio Cruz Siqueira ${ }^{2} \&$ Luciene Kazue Tokura $^{2}$ \\ ${ }^{1}$ Graduate Program, Master's in Agricultural Engineering, State University of West Paraná, Cascavel, Paraná, \\ Brazil \\ ${ }^{2}$ Graduate Program, Master's in Engineering of Energy in Agriculture, State University of West Paraná, \\ Cascavel, Paraná, Brazil \\ Correspondence: Luciene Kazue Tokura, Graduate Program, Master's in Agricultural Engineering, State \\ University of West Paraná (UNIOESTE), Rua Universitária, 2069-Jardim Universitário, Cascavel, Paraná, Brazil. \\ Tel: 55-453-220-3135. E-mail: lucienetokura@gmail.com
}

Received: October 8, 2018

Accepted: November 17, 2018

Online Published: January 15, 2019

doi:10.5539/jas.v11n2p192

URL: https://doi.org/10.5539/jas.v11n2p192

\begin{abstract}
This trial goes along with irrigation systems based on the development and use of free software and hardware for direct measurements of soil moisture and temperature throughout the plant cycle. Thus, irrigation systems can optimize water use during the process at lower cost regarding TDR application. Four humidity sensors were used: one was resistive, and three capacitors were interconnected in a mesh network system. Thus, this research was carried out in laboratory and the studied soil was characterized as a typical dystroferric Red Latosol (Oxisol) with very clayey texture (66\%). Soil clods were undone and dried in a greenhouse, then divided in 20 containers with addition of known volumes of water in each one. A network of mesh-type node sensors has been developed based on Arduino technology to read and transmit data to a single gateway. The sensor node was designed and built with Arduino Nano, radio NRF24L01, capacitive sensors of type SHT20 and DHT22, in addition to FC-28 that is resistive. The system also featured a Real Time Clock DS1302, three photovoltaic cells and circuit battery charger. Domoticz software was used to store data and make them available on a server connected to the internet. Cubic modeling was one of the results of the relation among each sensor, TDR and the greenhouse method. The resistive sensor showed very close values to the TDR in its model as well as the set of the monitoring system showed low cost in relation to TDR.
\end{abstract}

Keywords: sensors, TDR, arduino, mesh

\section{Introduction}

Drinking water of quality has been considered a finite resource for consumption and irrigation, so, its use must occur in a rational way in order to avoid wastes and contamination of aquatic sources (Helmer, 1997). Since irrigation is the main human consuming activity of water and considering the increase in energy costs and competition for water and energy resources among industrial, urban and agricultural sectors, it is relevant to define when and how much irrigation is needed in order to meet cropping water requirement (Mancosu et al., 2015).

In Brazil, water is used mainly for irrigation, human and animal consumption, industrial purposes, power generation, mining, aquaculture, navigation, tourism and recreation. Knowledge of these uses is constantly extended through direct surveys, sectoral studies and user registrations (National Water Agency, 2018). At the moment, irrigation is the main use of water in Brazil. Total demands for water withdrawn for irrigation in Brazil reach $969 \mathrm{~m}^{3} \mathrm{~s}^{-1}$. This use is even more relevant when consumption is considered, as return flows directly into waterbodies are very low, compared to other uses (National Water Agency, 2018). Thus, irrigation management must provide conditions of water availability to the crops, which allow externalizing its genetic yield potential in order to decrease the financial burden and environmental impact (Elliott et al., 2014). Therefore, it is extremely important to identify the timing of water application (when irrigating) and quantify how much of it should be applied (how much to irrigate) in order to avoid stress or water excess during the cropping term (Fereres, \& Soriano, 2007). 
According to Frizzone (2012), irrigation systems can be classified as: surface irrigation, whose water distribution occurs by gravity through soil surface; sprinkler irrigation, in which water jets are thrown into the air and fall on the crop as rain; trickle irrigation refers to where water is usually applied in only a part of the root system in plants, using precise emitters (drippers), linear ones (porous or "gut" duct) or surface emitters (micro-sprinklers); sub-irrigation, groundwater is kept at a certain depth and can allow an adequate flow of water to the root zone of a crop. It is mostly associated with a subsurface drainage system and, when there are satisfactory conditions, it may be the cheapest method.

Frizzone (2017) also pointed out that there are several methods to determine soil water content. These methods have been evolving over time and fit to the technology advances. So, in order to obtain the details concerning several of these methods, it is possible to get information on texts written by Carvalho and Oliveira (2012), Andrade Júnior, Silva, and Coelho (2013), and Souza et al. (2016). Generally, these methods can be grouped into two categories: direct (or gravimetric) methods and indirect ones. Among the direct ones, that are also called as gravimetric methods, there are the forced-circulation (standard) oven drying, microwave oven drying and weighing methods. Indirect methods are based on measures of soil resistance to the passage of an electric current, dielectric constant of soil, soil water tension and neutral moderation (Van Genuchten, 1980; Carvalho, Sampaio, \& Silva, 1996; Topp \& Ferré, 2002; Queiroz, 2007; Lucas et al., 2011; Chari et al., 2013; Sui, 2018).

The Time Domain Reflectometry (TDR) is one of the most used methods, with a calibration curve to study soil, as presented by Tommaselli and Bacchi (2001) as well as Milani, Tavares, and Scherpinski (2008), and Jeewantinie Kapilaratne and $\mathrm{Lu}$ (2017). It is worth noting that TDR is a high-precision and cost-effective device. However, its use is unfeasible for some simultaneous collection of data distributed at several points in the farm because, to probe some soil variability, cables and rods must be spread out in all directions and at great distances, exceeding the limits of this technology. So, this trial aimed at developing hardware and software for an automated data collection system, in variables such as soil moisture and temperature, in several points, using free technologies for irrigation systems as another viable field monitoring option.

\section{Material and Methods}

\subsection{Sensor Node Design}

The Arduino Nano was used as a microcontroller for the Node of sensor network, with the following dimensions: $18 \times 45 \mathrm{~mm}$, Flash memory of 32 Kbytes, 8 analog inputs/outputs, 22 digital inputs/outputs and consumption 19 $\mathrm{mA}$ in $5 \mathrm{~V}$. A two-way communication between Nodes and Gateway was performed by radio NRF24L01. The digital humidity and temperature sensors were SHT20 and DHT22 (this last one in two versions). In addition, the FC-28 analogue humidity resistive sensor was used, and the Real Time Clock (RTC) DS1302 was also used to establish temporal synchronism among readings. The system was powered by a $9-\mathrm{V}$ rechargeable battery, which is charged by an LM317 composite circuit, diodes, resistors and three solar panels of $5 \mathrm{~V}$ and $200 \mathrm{~mA}$ each. Figure 1 shows the Sensor Node circuit. 


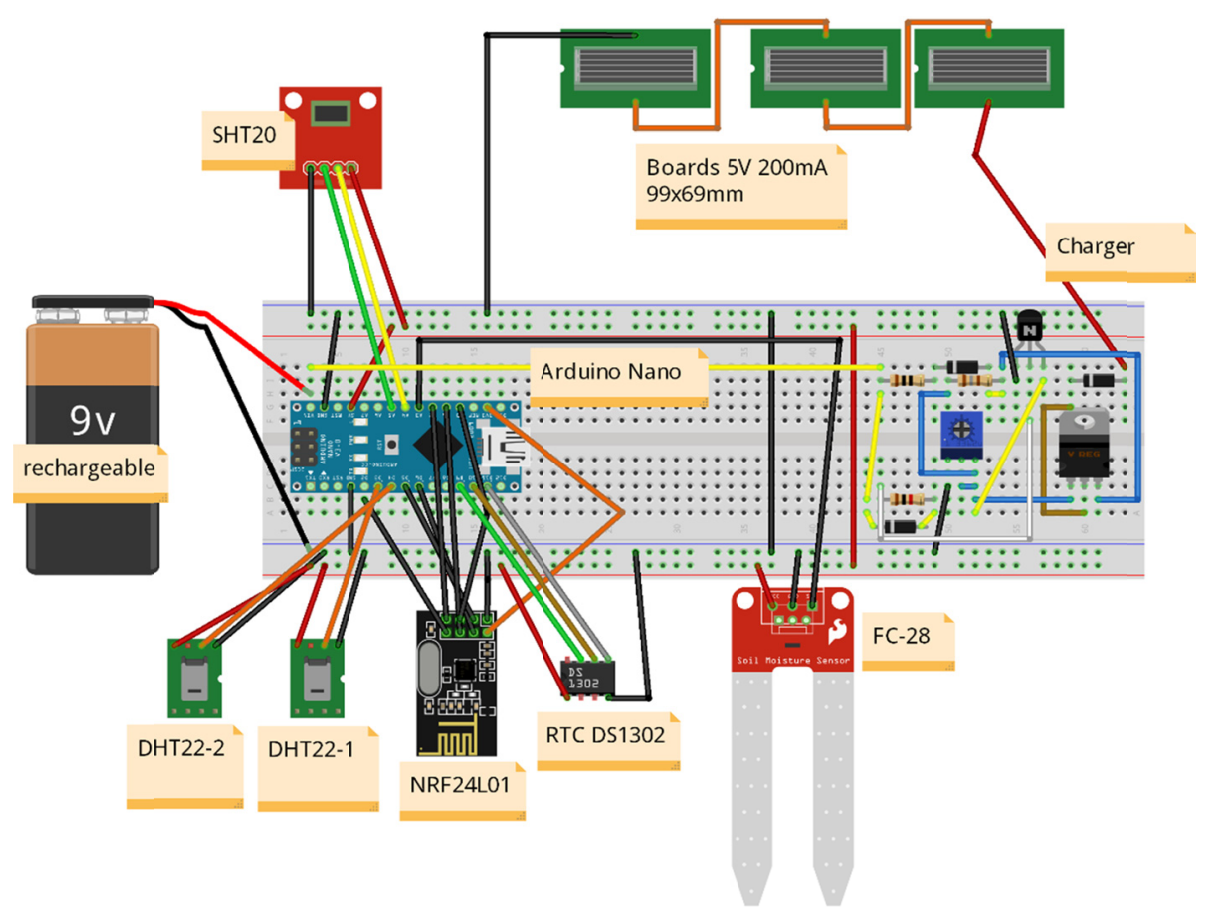

Figure 1. Sensor node circuit

Note. Image built using Fritzing software.

Four sensors are connected in a fiberglass board circuit plus the Sensor Node board. DHT22 and SHT20 are capacitive humidity sensors that also measure temperature, while FC-28 is a resistive humidity sensor and DHT22-1 is a physical change in DHT22 sensor casing. The DHT22-1 sensor was made by enlarging the air chamber of a standard DHT22 sensor. The original air chamber of DHT22 sensor was replaced by a semi-sphere (6.5-cm diameter) of ABS (Acrylonitrile-Butadiene-Styrene), covered by a 65-wire silkscreen screen, which allows the passage of moist air.

\subsection{Gateway Design}

The Gateway is designed over the Arduino Uno and internet connection by Arduino Ethernet Shield W5100, as Figure 2 shows.

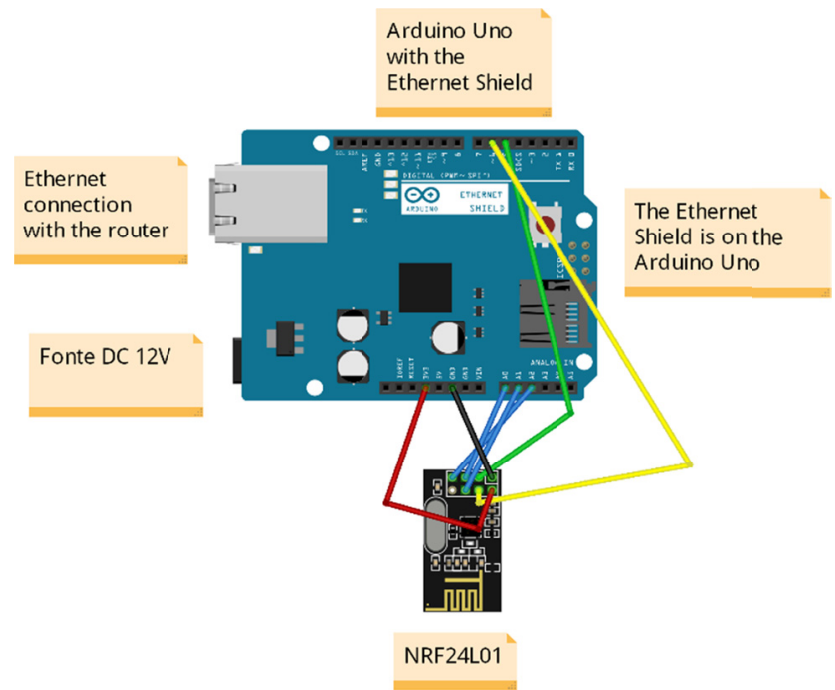

Figure 2. Gateway circuit

Note. Image built using Fritzing software. 
The Gateway is connected to Sensor Nodes on NRF24L01 radio at a maximum distance of 100 meters. The Sensor Nodes and Gateway store the smallest path for data transmission after initialization in its non-volatile memory.

When a Sensor Node is connected, a startup package is sent by radio. If the package is received directly by the Gateway, it will provide an identification number for the requestor and will return a response to the Node that began the dialog via radio. If the Sensor Node is physically far from the Gateway (more than $100 \mathrm{~m}$ ) and cannot communicate directly, one or more Sensor Nodes may act as intermediaries to send the data packets. The startup package identifies the sensor and the type of data it provides, humidity, temperature, or voltage. This allows that a Sensor Node can be inserted into network at any time.

A radio network can consist of up to 254 different radio nodes and each radio node can transmit data for up to 254 sensors. In this case, it is possible to manage data of up to 64,516 sensors in a single radio network. There is also the possibility of creating parallel radio networks with 126 channels available for NRF24L01. Thus, the radio meets the needs for the requested monitoring activity.

\subsection{The Communication Diagram}

The communication diagram, shown in Figure 3, represents the entire flow of messages among the hardware system components. The user, who can be a person or any other system, receives data of all sensors monitored in network through an address in the web browser. The device can be a tablet, a smartphone or a computer.

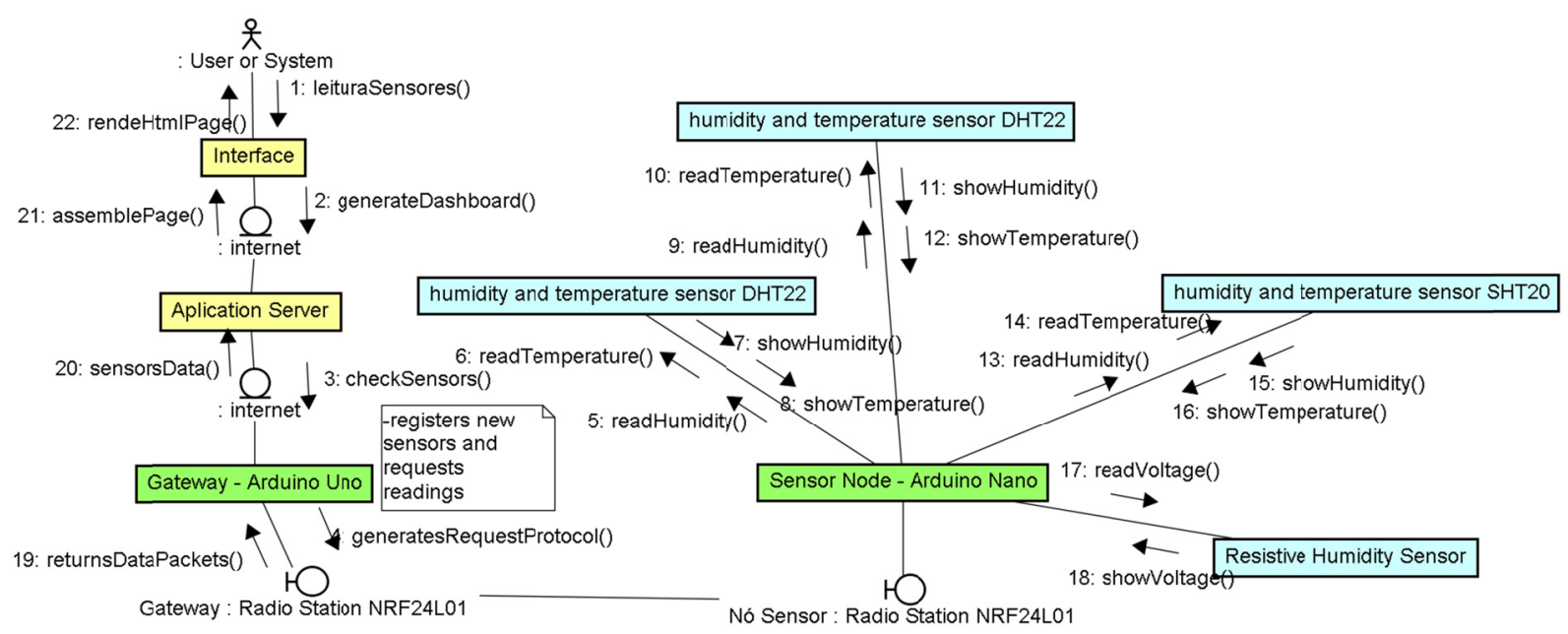

Figure 3. Communication diagram for the reading system

\subsection{Software Design}

The programming of Arduino boards was carried out in an available development environment offered by the board's manufacturer, in version 1.6.7 for the Windows 10 operating system. The routines for humidity and temperature sensors readings were developed using outsourced party free libraries that follow the software environment package, plus MySensor, DHT, SHT2x and Wire libraries.

Radios were chosen in the market due to their lowest price and highest performance, which allowed communication among Arduino modules and the set of free libraries to guarantee communication among Sensor Nodes and Gateway of the mesh network. There were installation and configuration of Arduino Uno with Shield W5100 Ethernet card and digital radio cards (gateway), routines for radio communication on Arduino Nano (Sensor Node), routines to read the Real Time Clock circuits (RTC) DS1302 as well as the server to receive data from the sensor nodes through the gateway.

\subsection{Preparation of Sample Units}

Twenty sample units were built with 10 -cm-diameter containers by $50 \mathrm{~cm}$ in height in PVC. And, $2.5 \mathrm{~kg}$ of typical dystrophic Red Latosol (EMBRAPA, 2013) air-dried soil were added to each sample unit, according to methodology proposed by Maciel et al. (2017). Soil was collected from 0 to $20 \mathrm{~cm}$ depths at the Experimental Nucleus of Agricultural Engineering (ENAE), in Cascavel city, Paraná state, at coordinates 24 $53^{\prime} 59.85^{\prime \prime}$ S, $53^{\circ} 32^{\prime} 1.98^{\prime \prime} \mathrm{W}$ and $750 \mathrm{~m}$ altitude. 
Residual soil moisture and saturation moisture were determined just after soil collection. The interval between residual moisture and soil capacity was divided into 20 parts, in order to obtain moisture for each sample unit, according to Tommaselli and Bacchi (2001) recommendations. Water mass was added in each container and established by subtracting the residual moisture value from the desired moisture. Water mass was sprayed onto soil mass in a container and, after stirring, soil was sieved twice consecutively, with a 2-mm mesh, and then, it was put into the same container again. The container was sealed and stirred for ten days periodically to homogenize moisture throughout the profile.

\subsection{Experimental Management}

The experiment was carried out indoors with controlled temperature, moisture and luminosity. The twenty sample units were randomly arranged, and each sample received the same amount of soil.

One of the tubes that already contained soil was taken, then, sensors connected to the Sensor Node and the $20-\mathrm{cm}$ probe of TDR were inserted into this tube, which was closed at the end. Five readings were recorded on each sensor at every two hours and their average was calculated. This action was repeated for each tube. Then, in total, twenty measurements of moisture, temperature, voltage, dielectric constant and volumetric humidity were collected.

Among the readings of measurements from one tube to the other, sensors were removed, left under shelter and at room temperature for two hours so that the readings in other tubes with the same sensors did not undergo the effect of previous measurements and were resilient, before measuring them again.

\subsection{The Arduino Nano}

Arduino Nano was used as a microcontroller for $18 \times 45-\mathrm{mm}$ sensor network node, 32 Kbytes Flash memory, eight analog inputs and outputs and twenty-two digital inputs and outputs. Consumption is also minimal when compared to others from Arduino series, $19 \mathrm{~mA}$ at 5V. The NRF24L01 radio was used for bi-directional communication among nodes and Gateway. The digital humidity and temperature sensors used were SHT20 and DHT22. The humidity resistive sensor, which is analog, was FC-28, while the Real Time Clock DS1302 was used to establish temporal synchronism among the readings. The system was powered by a rechargeable $9-\mathrm{V}$ battery, which was kept loaded by a circuit composed of one LM317, diodes, resistors and three solar panels of $5-\mathrm{V}$ and $200 \mathrm{~mA}$ each, as it is shown in Figure 1 of the Sensor Node.

\section{Resultes and Discussion}

\subsection{Prototype Assembled With the Sensors}

The assembled and welded circuit in glass fiber board is shown in Figure 4.

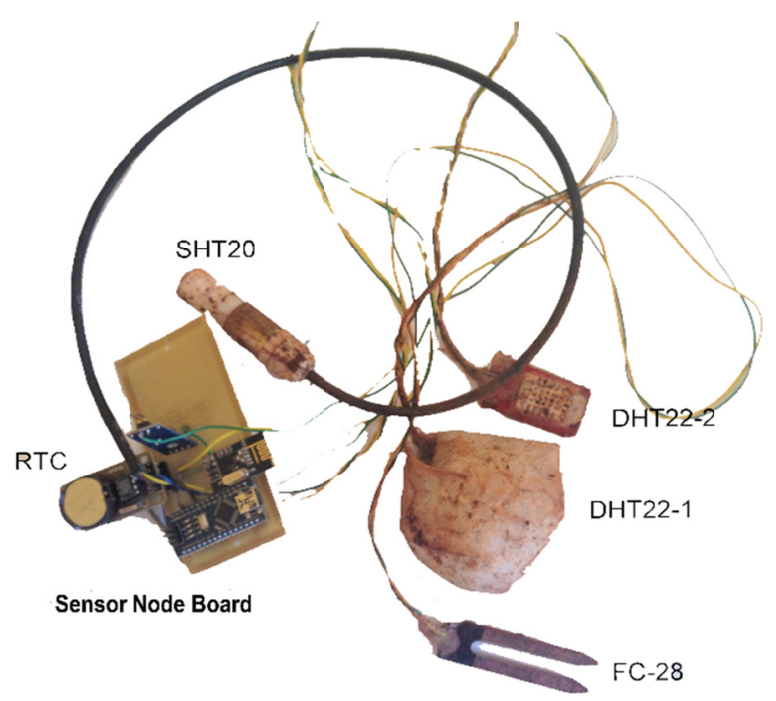

Figure 4. Prototype sensor node assembled with the sensors

Four devices can be seen in figure below, which are connected to the Sensor Node board. DHT22 (2) and SHT20 are capacitive humidity sensors that also measure temperature, while FC-28 is a resistive humidity sensor. The 
air chamber of DHT22-1 sensor was enlarged by an ABS semi-sphere (Acrylonitrile-Butadiene-Styrene) manufacturing, printed on a 3D printer, Figure $5 \mathrm{c}$.
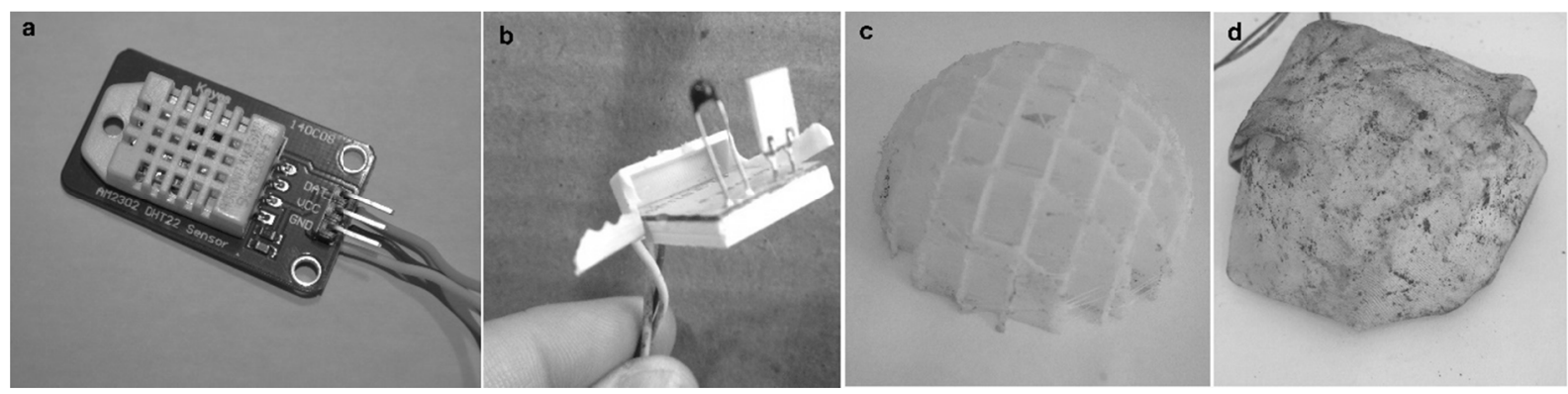

Figure 5. Modified DHT22 sensor; a: the original one; b: without casing; c: hemisphere of ABS; and d: final result with the sensor inside the casing and with an applied screen

The white casing was taken out from DHT22, which can be observed in Figure 5a. Thus, the design remained as shown in Figure 5b. It is worth mentioning that the hemisphere diameter is $6.5 \mathrm{~cm}$ wide. And, Figure $5 \mathrm{~d}$ shows the result after encasing hemisphere with a very thin silkscreen screen, which allows the passage of moist air.

The Gateway is designed based on Arduino Uno with the connection of an Arduino Ethernet Shield W5100. The Shield W5100 connects Arduino Uno through a cable with RJ45 connector on internet through a network point. So, in order to connect the Gateway to the Sensor Nodes in a logical way, NRF24L01 radio was physically connected to the set according to Figure 2. The communication diagram, shown in Figure 3, represents the entire flow of messages among the components of the hardware system. This user, which can be a person or any other system, receives data of all sensors monitored in the network from an address on the web browser. The device can be a tablet, a smartphone or a computer.

When a Sensor Node is connected, a startup package is sent by radio. If the package is received by Gateway, it will provide an identification number to the requestor and a response will come back by radio to the Node that began the dialog. If other nearby Sensor Nodes receive the startup package, they will retransmit it by radio to one another aiming at reaching the Gateway. Nodes also retransmit the response to the booting request from other Nodes that have come from Gateway. Therefore, if there is physical proximity among the radios, all Nodes will be able to be identified numerically and by their type. This allowed that at any time a Sensor Node could be inserted into network. The startup package identifies the sensor and the kind of data that it provides humidity, temperature or voltage. The Sensor Nodes and Gateway store in their non-volatile memory the smallest path for data transmission after booting.

Such radio network may consist of up to 254 different radio nodes and each one may report data to 254 sensors connected to the network. This means that, in theory, you can manage data for up to 64,516 sensors on a single radio network. If this is not enough, you can create another parallel radio network on a different channel and there are 126 channels available for NRF24L01, so, it will comply with the aimed monitoring activity.

\subsection{Line Graphs Adjusted by Cubic Regression Model}

After readings have been accomplished, with values measured according to the greenhouse method, by TDR and humidity sensors, the line graphs adjusted by cubic regression model are presented, then, it was possible to analyze data applied to Figure 6 . 


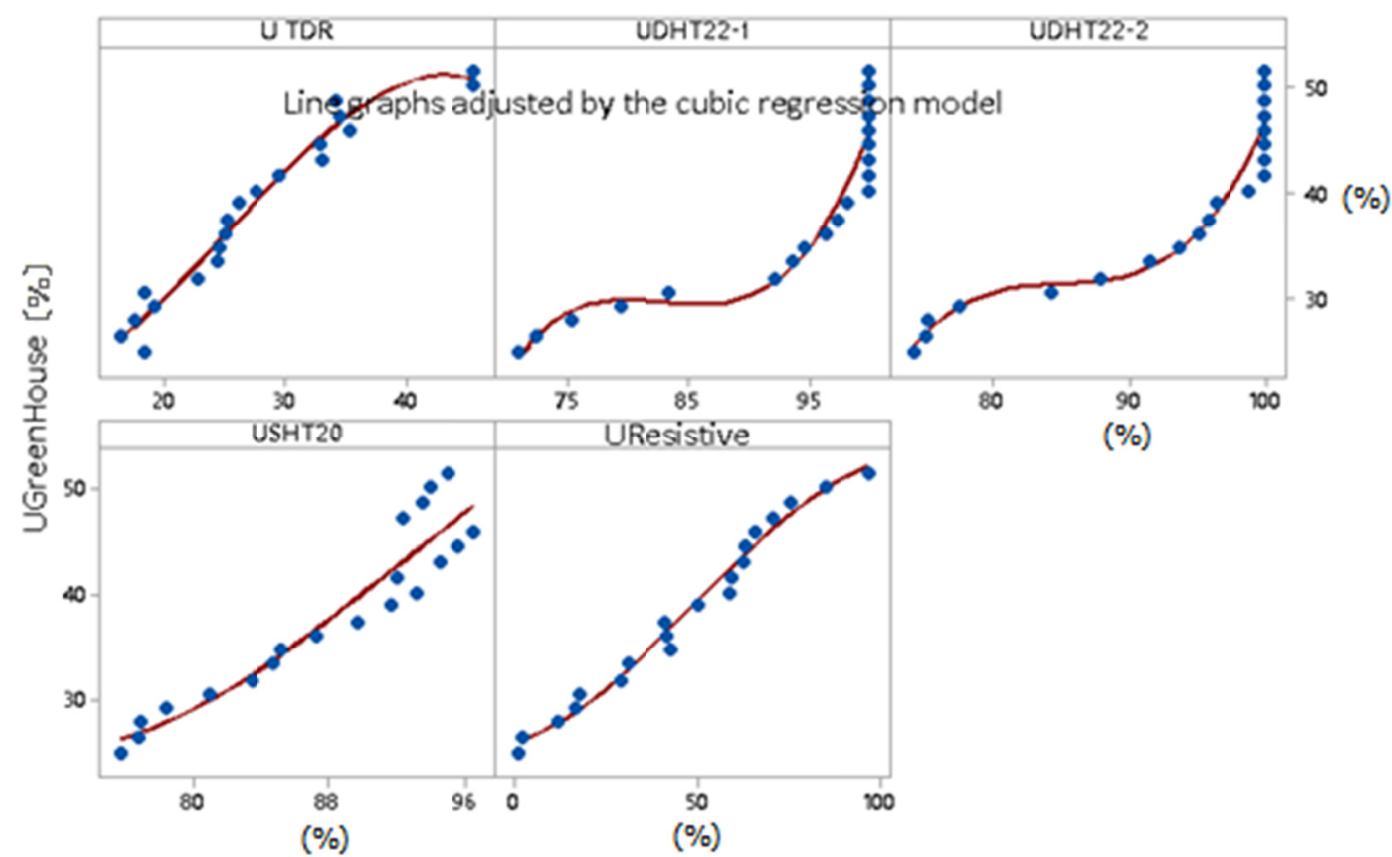

Figure 6. Line graphs adjusted by cubic regression model among humidity readings of sensors and the greenhouse standard

Visually, it was observed that the cubic model has adapted itself to all the adjustment curves. Tommaselli and Bacchi (2001) and Jeewantinie Kapilaratne and $\mathrm{Lu}$ (2017) claim that such models are simple and practical to establish the calibration curves of TDR equipment. Points above $92 \%$ on SHT20 sensor have the largest waste when compared to the other curves. The resistive sensor presents a similar curve, in form and parameters to TDR and both DHT22 sensors showed very similar behavior between each other.

The DHT22 and SHT20 sensors display readings of humidity values well above the expected ones, and even DHT22 sensors limit the actual humidity value to close to $47 \%$. Therefore, values superior to what has be shown here are not allowed, that is, when a sensor generates a value of $98 \%$ or above this, and when compared to the gold standard, actually, the model equation will always result in a $47 \%$ value, even when humidity is well above such answer. Another negative characteristic that was observed by DHT22 sensors was that, when they provide a reading between $80 \%$ and $90 \%$ humidity, the real value, if the regression model is applied, will vary from $29 \%$ to $31 \%$, ie, the error was greater because a $10 \%$ variation generated only $2 \%$ variation of the real value.

The "p-value" for the regression model, in all equations, shows that models estimated by regression procedure are significant at 0.05 level for each one, since $\mathrm{p}<0.05$ in all of them. It was also necessary to analyze the regression equations $1,2,3,4$ and 5 , the so-called adjustment curves.

$$
\begin{gathered}
\mathrm{U}_{\text {greenhouse }}=24.17-1.052 \mathrm{U}_{\mathrm{TDR}}+0.09123 \mathrm{U}_{\mathrm{TDR}}{ }^{2}-0.001214 \mathrm{U}_{\mathrm{TDR}}{ }^{3} \\
\mathrm{U}_{\text {greenhouse }}=-2022+74.42 \mathrm{U}_{\mathrm{DHT} 22-1}-0.8988 \mathrm{U}_{\text {DHT22-1 }}{ }^{2}+0.003614 \mathrm{U}_{\mathrm{DHT22}-1}{ }^{3} \\
\mathrm{U}_{\text {greenhouse }}=-2522+90.09 \mathrm{U}_{\text {DHT22-2 }}-1.060 \mathrm{U}_{\text {DHT22-2-2 }}{ }^{2}+0.004162 \mathrm{U}_{\text {DHT22-2-2 }}{ }^{3} \\
\mathrm{U}_{\text {greenhouse }}=814-27.88 \mathrm{U}_{\mathrm{SHT} 20}+0.3185 \mathrm{U}_{\mathrm{SHT} 20}{ }^{2}-0.001159 \mathrm{U}_{\mathrm{SHT} 20}{ }^{3} \\
\mathrm{U}_{\text {greenhouse }}=25.91+0.1020 \mathrm{U}_{\text {resistive }}+0.005017 \mathrm{U}_{\text {resistive }}{ }^{2}-0.000034 \mathrm{U}_{\text {resistive }}{ }^{3}
\end{gathered}
$$

When a coefficient of degree 3 of adjustment models' equations was observed, the model for humidity in resistive sensor (5) has almost no influence on humidity up to $35 \%$. In equations obtained for capacitive sensors, DHT22 (2 and 3) and SHT20 (4), the independent term shows a very large discrepancy in relation to TDR (1) and FC-28 (5). Thus, it is assured that the very high values on humidity reading at the beginning generated such different result.

Theoretically, it is known that during the analysis of variance of data, if a model were able to explain $100 \%$ of variance, the adjusted values would always be equal to the observed ones, consequently, all data points would be 
along the adjusted regression line. Thus, determination coefficients were obtained in order to compare the models of equations $6,7,8,9$ and 10 .

$$
\begin{gathered}
\mathrm{R}_{\text {TDR }}^{2}=96.9 \% \\
\mathrm{R}_{\text {DHT22-1 }}^{2}=90.1 \% \\
\mathrm{R}_{\text {DHT22-2 }}^{2}=92.7 \% \\
\mathrm{R}_{\text {SHT20 }}^{2}=89.0 \% \\
\mathrm{R}_{\text {Resistive }}^{2}=98.5 \%
\end{gathered}
$$

Based on these answers, $\mathrm{R}^{2}$ values have shown that the models that best explain the relation among the values obtained by the gold standard method are TDR (6) and the resistive sensor (10), although the other sensors also present good coefficient of determination. And, considering the analysis of variance, the standard error of regression $(\mathrm{S})$ is another measure that allows the comparison among models, in which the smallest value indicates the best model:

$$
\begin{gathered}
\mathrm{S}_{\mathrm{TDR}}=1.58906 \\
\mathrm{~S}_{\text {DHT22-1 }}=2.83434 \\
\mathrm{~S}_{\text {DHT22-2 }}=2.4295 \\
\mathrm{~S}_{\mathrm{SHT20}}=2.98157 \\
\mathrm{~S}_{\text {Resistive }}=1.11613
\end{gathered}
$$

In this specific issue, two previous regressions are still the best ones: the TDR (11) and the resistive sensor (15), however, the resistive one comes out as the best one based on the calculus of the standard deviation regarding wastes.

\section{Conclusion}

The hardware designs of Gateway and Sensor Node have worked properly for the requirement to use free technologies and the platform used by Arduino confers this feature. They take up little physical space, they also have low power consumption, high performance, and the price of their components are far below those presented by many other technologies. The battery system allows operation without recharging up to 36 hours and, with the sun, the photovoltaic cells can guarantee uninterrupted operation.

The applied sensors and radio had very low cost and it has been demonstrated that it is feasible to use all the devices, mainly, the resistive one. It should be highlighted that this or the other capacitive ones can replace TDR use to register humidity, and it can also apply the correction according to the curves obtained in this research.

The embedded software used MySensors library, which is a free-technology, licensed by GPL V2. The Free/Open Source application server receives data that are sent by the Gateway and makes them available on internet, while the whole source code is available and can be changed. The use of Mesh network, from MySensors library, has guaranteed data delivery to the Gateway, without flaws. Data can go from the sensor to the gateway and internet or vice versa; in addition, remote commands can be given to the Sensor Node by the web interface. Finally, data analysis showed that the use of proposed sensors is feasible and resulted in a model to be applied for each device.

\section{References}

Andrade Júnior, A. S., Silva, C. R., \& Coelho, E. F. (2013). Monitoramento do teor de água no solo. In A. Aguiar Netto, \& E. A. Bastos (Eds.), Princípios agronômicos da irrigação (p. 262). Brasília, DF: Embrapa.

Carvalho, D. F., \& Oliveira, L. F. C. de. (2012). Planejamento e manejo da água na agricultura. Viçosa, MG: Editora UFV.

Carvalho, L. G. de, Sampaio, S. C., \& Silva, A. M. da. (1996). Determinação da umidade na capacidade de campo in situ de um Latossolo Roxo distrófico. Engenharia Rural, 7, 91-97.

Chari, M. M., Nemati, F., Afrasiab, P., Kahkhamoghaddam, P., \& Davari, A. (2013). Prediction of evaporation from shallow water table using regression and artificial neural networks. Journal of Agricultural Science, 5(1), 168-180.

Elliott, J., Deryng, D., Müller, C., Frieler, K., Konzmann, M., Gerten, D., ... Wisser, D. (2014). Constraints and potentials of future irrigation water availability on agricultural production under climate change. Proceeding 
of the National Academy of Sciences of the United States of America, 111(9), 3239-3244. https://doi.org/ 10.1073 pnas. 1222474110

EMBRAPA (Empresa Brasileira de Pesquisa Agropecuária). (2013). Sistema Brasileiro de Classificação de Solos. Centro Nacional de Pesquisa de Solos (3rd ed.). Rio de Janeiro: Embrapa.

Fereres, E., \& Soriano, M. A. (2007). Deficit irrigation for reducing agricultural water use. Journal of Experimental Botany, 58, 147-159. https://dx.doi.org/10.1093/jxb/erl165

Frizzone, J. A. (2012). Os métodos de irrigação. Manual de Irrigação, 32. Piracicaba: ESALQ/USP.

Frizzone, J. A. (2017). Necessidade de água para irrigação. Piracicaba: ESALQ/USP.

Helmer, I. H. R. (1997). Water Pollution Control-A Guide to the Use of Water Quality Management Principles E \& FN Spon. London, Great Britain.

Jeewantinie Kapilaratne, R. G. C., \& Lu, M. (2017). Automated general temperature correction method for dielectric soil moisture sensors. Journal of Hydrology, 551, 203-2016. https://doi.org/10.1016/j.jhydrol. 2017.05.050

Lucas, J. F. R., Tavares, M. H. F., Cardoso, D. L., \& Cássaro, A. M. (2011). Soil-water retention curve by the filter paper method. Revista Brasileira de Ciências do Solo, 35(6), 1957-1973. https://doi.org/10.1590/S0100-0683 2011000600013

Maciel, A. P. C., Sampaio, S. C., Remor, M. B., Rosa, D. M., \& Reis, R. R. dos. (2017). Soil meso- and macrofauna in two soybean crops after swine wastewater application. Engenharia Agrícola, 37, 556-564. https://doi.org/10.1590/1809-4430-eng.agric.v37n3p556-564/2017

Mancosu, N., Snyder, R. L., Kyriakakis, G., \& Spano, D. (2015). Water scarcity and future challenges for food production. Water, 7, 975-992. https://doi.org/10.3390/w7030975

Milani, D. I. C., Tavares, M. H. F., \& Scherpinski, C. (2008). TDR probes calibration in laboratory conditions. Ambi-Água, 3, 68-75. http://dx.doi.org/10.4136/ambi-agua.43

National Water Agency. (2018). Brazilian Water Resources Report-2017 (p. 169). Brasília: ANA.

Queiroz, T. M. (2007). Desenvolvimento de um sistema automático para irrigação de precisão em pivô central (141 f., Tese de doutorado em Agronomia, Escola Superior de Agricultura "Luiz de Queiroz", Piracicaba).

Souza, C. F., Silva, C. R. da, Andrade Junior, A. S. de, \& Coelho, E. F. (2016). Monitoring of soil water content in real time with TDR and FDR technique. Irriga, 1, 26-42. https://doi.org/10.15809/irriga.2016v1n01p26-42

Sui, R. (2018) Irrigation scheduling using soil moisture sensors. Journal of Agricultural Science, 10(1), 1-11. https://doi.org/10.5539/jas.v10n1p1

Tommaselli, J. T. G., \& Bacchi, O. O. S. (2001). Calibration of a TDR equipment to moisture measurement in soils. Pesquisa Agropecuaria Brasileira, 36(9), 1145-1154. https://doi.org/10.1590/S0100-204X2001000900008

Topp, G. C., \& Ferré, P. A. (2002). The soil solution phase. In J. H. Dane, \& G. C. Topp (Eds.), Methods of soil analysis (pp. 417-1071). Wisconsin: Soil Science Society of America.

Van Genuchten, M. Th. (1980). A closed-form equation for predicting the hydraulic conductivity of unsaturated soils. Soil Science Society American Journal, 44, 892-898. https://doi.org/10.2136/sssaj1980.036159950 04400050002x

\section{Copyrights}

Copyright for this article is retained by the author(s), with first publication rights granted to the journal.

This is an open-access article distributed under the terms and conditions of the Creative Commons Attribution license (http://creativecommons.org/licenses/by/4.0/). 